\title{
Final Design And Manufacturing Of The Cryolegs Of The W7-X- Superconducting Coil Support System
}

H. Jenzsch1), A. Cardella1), J. Reich1), W. Gardebrecht1), M.Bednarek1), P. Sanchez1), M. Schrader1)

1) Max-Planck-Institut für Plasmaphysik, EURATOM Association, Teilinstitut Greifswald Wendelsteinstraße 1, D-17491 Greifswald, Germany (email:hartmut.jenzsch@ipp.mpg.de, phone: +49-3834-88-2215, fax: +49-3834-882709

\begin{abstract}
One of the most complicated tasks during the assembly of the WENDELSTEIN W7-X is the installation of the superconductive coil system.

The entire magnet system is enclosed between the Outer Vessel and the plasma vessel in high vacuum at $4 \mathrm{~K}$.

The coils are supported by a support structure, the Central Support Structure (CSS).

The CSS carries all 70 coils, and it is designed as a closed ring made of 5 modules (10 half modules). The whole structure is supported by $\mathbf{1 0}$ Cryolegs which rest on the machine base.

This paper describes the final design and manufacture of these Cryolegs

Central Support Structure, Cryoleg, Wendelstein W7-X
\end{abstract}

\section{Introduction}

The Wendelstein $\mathrm{W} 7-\mathrm{X}$ is a fusion experiment which is currently under construction in the Greifswald branch of IPP. Its coil system with its CSS is within the cryostat at $4 \mathrm{~K}$ and under high vacuum. Figure 1 shows a schematic cut through the Cryostat.

The CSS stands on 10 vertical supports that separate the CSS at cryogenic temperature from room temperature. These supports are called Cryolegs. The Cryolegs as vertical support elements of the whole magnet system are static highly loaded components and are located inside the cryostat supporting cylindrical legs. The Cryolegs are at cryogenic temperature at the connection with the CSS and at room temperature at the machine base. Stainless steel bellows are used between the Cryolegs and the cryostat supporting legs.

The Cryolegs fulfill five substantial tasks:

- Transmission of high vertical and horizontal forces $(\max F v=1 \mathrm{MN}$, $\max \mathrm{Fh}=156 \mathrm{kN})$

- Compensation of different thermal expansions between the Central Support Structure (CSS) at $4 \mathrm{~K}$ and the machine base at room temperature

- Thermal insulator between the cold parts (CSS / coil system) and the warm structure

- Compensation of manufacture and assembly tolerances between the CSS and the Outer Vessel (OV)

- Vertical and horizontal adjustment of the CSS on the machine-base
All components of the Cryolegs, except the insulator bush see Fig. 4, are made of stainless steel 1.4429 316LN (yield point Rp 0,2: $>900 \mathrm{MPa}$ at $4 \mathrm{~K}$, elongation at fracture: $>25 \%$, Young's modulus : $>190 \mathrm{GPa}$ at $4 \mathrm{~K}$, cobalt content $<500$ ppm).

$1 / 6 \mathrm{pp}$

Fig. 1: Schematic view of main Cryostat components of the WENDELSTEIN 7-X

\section{Design of Cryolegs}

Per module two Cryolegs ensure the support of the modular installed coils and its CSS.

One module is shown in fig. 2.

$1 / 6 \mathrm{pp}$

Fig. 2: Module representation of CSS with Cryoleg-

The Cryoleg is able to resist the bending moments. Its top part is bolted to a lower flange of the CSS. 
Each connection is made with $3 \mathrm{M} 33$ and $3 \mathrm{M} 30$ Inconel studs, see table 1 . The defined pre-loading is realized using superbolt-nuts at all screws.

The foot parts (bearing components) of the Cryolegs make possible the rotation and also the horizontal sliding on the machine basis.

For the toroidal restraining and the centring of the CSS tie rods are used at the base plate of the Cryolegs. The tie rods allow the radial displacements due to thermal expansion of the structures.

$1 / 6 \mathrm{pp}$

Fig. 3: Sketch of the statical system

\section{Function and structure of the Cryoleg com- ponents \\ The Cryoleg consists of 5 functional components: \\ Ring fitting \\ Insulator bush \\ Bearing components \\ Bellow \\ Tie rod, (centering component)}

$1 / 6 \mathrm{pp}$

Fig. 4: Structure of Cryolegs

The 10 Cryolegs are identically designed. Within a module there are only slight constructional deviations in the upper flange plate.

The upper parts of Cryolegs are computed and designed for the transmission of high vertical and horizontal forces.

The overall length of one Cryoleg is $1,54 \mathrm{~m}$. During the experiment time they have to withstand a maximum bending moment of $\mathrm{Mb}=234 \mathrm{kNm}$ at the top of the Cryoleg, see table 2.
$1 / 6 \mathrm{pp}$

Table 1: Bolt connection both Cryoleg upper flange to the CSS [5]

$1 / 6 \mathrm{pp}$

Table 2: Forces and bending moments in Cryoleg parts [5]

\subsection{Ring fitting design}

The Ring fitting is a welded construction with 4 external stabilizing ribs. The connection between the pipe and the two flanges is achieved by EBwelding.

The connection of the external ribs is implemented by conventional welding.

\subsection{Insulator bush function and design devel- opment}

Prior to plasma operation time the coils and the CSS have to be cooled down to $4 \mathrm{~K}$ with an active cooling system with liquid Helium (He). Therefore, during the operation, the upper parts of the Cryolegs are at $4 \mathrm{~K}$, but the lower parts are at room temperature $(293 \mathrm{~K})$. For this reason the Cryolegs must have an intermediate element with enough strength, but with a very low thermal conductivity to withstand the loads and minimize the thermal losses. This intermediate element is the thermal insulator bush of the Cryolegs. 


\section{$1 / 6 \mathrm{pp}$}

Fig. 5: Structure of Insulator bush

The Insulator bush is a glass reinforced plastic (GRP) tube with two main stainless steel (1.4429) flanges in the upper and lower extremes.

The upper steel flange has two parts, the inner ring and the outer ring, connected with 12 bolts M20. The upper outer ring has to be connected to a flange with 16 bolts M20 to the Ring fitting lower flange of the Cryoleg. This connection has to transmit a bending moment of $144 \mathrm{kNm}$.

At a defined height (with a level of 80K) the GRP bush of the Insulator bush has a heat conducting system made of an external fixed copper ring and internal fixed copper disk (material OFHC).

It has to transfer the heat from inside the Cryoleg to the thermal insulation shield.

For the realization of the stringent mechanical and heat conducting requirements in combination with high vacuum, the following characteristics were specified:

- Fiber material (R-Glass) and matrix material (epoxy resin) have to be free of Bromine and Boron, so a minimum radiation resistance of $1 \mathrm{E} 7 \mathrm{rad}$ (1E5 Gy) can be guaranteed.

- Thermal contraction from $293 \mathrm{~K}$ to $4 \mathrm{~K}$ $(\Delta \mathrm{T}=289 \mathrm{~K})$ in several planes of the GRP bush, see table 3

- Mechanical properties at room temperature and at $80 \mathrm{~K}$ like Young's modulus and strengths in several planes of the bush, see table 4,5

\footnotetext{
$1 / 6 \mathrm{pp}$

Table 3: Thermal contraction in several planes of the GRP bush [2]
}

Table 4: Young's modulus several planes of the GRP bush [2]

$1 / 6 \mathrm{pp}$

Table 5: Strengths in several planes of the GRP bush [2]

The Cryoleg design has been analysed using the code ANSYS. The Cryolegs have been inserted in the large global FEM model of the coil supporting structures.

The results of the analyses have shown the suitability of the design from the structural and thermal point of view.

An R\&D task has been launched to develop and test this GRP material. After the manufacture of two prototypes a mechanical test shall examine the capability of the complete Insulator bush to withstand maximum loads. In figure 6 is shown a schematic experimental setup for load test.

Important data of the test:

- Vertical load

$1 \mathrm{MN}$

- Horizontal load

$156 \mathrm{kN}$

- Number of load cycles

- Load duration $60 \mathrm{~s}$

- Number of thermal cycles 50

- Load test will be performed at 77K

- Examination by force displacement diagram near the force point in horizontal and vertical direction 
Fig. 6: Schematic experimental setup for load test [3]

\subsection{Bearing components - function and design} The Bearing component fulfills the function of a static floating bearing, whose degree of freedom in toroidal direction of the torus system is restrained by one tie rod, see fig. 2 and 3 .

The Cryoleg bearing consists of one spherical and one plane sliding bearing component. The bearing should allows the radial thermal expansions/contractions and rotations due to deformations of the CSS but restricts toroidal movements. The spherical bearing avoids bending moments of Cryolegs at the machine base.

This system also keeps the CSS centered.
$1 / 6 \mathrm{pp}$

Table 7: Cycles to reach the maximum loads for planar bearing [4]

\subsection{Tie rods}

The Tie rods are revolving attached at one side to the foundation of the machine and on the other side to a base plate between the spherical and the plane bearing components.

The horizontal fixation of the CSS on the machine base is achieved with the help of the Tie rods.

The length of the Tie rods is adjustable. The Tie rods consist of two M48 threaded rods with joint eyes of austenitic high-grade steel and an adjustable nut.

\section{$1 / 6 \mathrm{pp}$}

\section{$1 / 6 \mathrm{pp}$}

Fig. 7: Design of the bearing assembly

The material of all bearing components is stainless steel 1.4429.

A special coating - fiberslip - of the sliding surfaces on the components ensures a maintenance-free operation during the life span of 15 years with a friction factor $\leq 0,05$ and a minimum radiation resistance of 1E7 rad (1E5 Gy). Fiberslip is a selflubricating material.

An extensive test campaign with 2 prototypes has been launched. This should demonstrate that the bearings will function as designed for a life span of at least 15 years, see in table 6 and 7.

\section{$1 / 6 \mathrm{pp}$}

Table 6: Cycles to reach the maximum loads for spherical bearing [4]
Fig. 8: Design of Tie rods

\subsection{Bellow}

The Bellows are the flexible connecting link between Cryolegs and the OV-legs.

The maximum working ranges for the Bellows are:

- lateral: $\quad \pm 40 \mathrm{~mm}$

- axial: $\quad \pm 25 \mathrm{~mm}$

Their tasks are:

- Compensation of manufacture and assembly tolerances between the CSS and the OV

- Compensation of the relative movements between Cryoleg and OV-leg induced by the different operating conditions of the magnetic system and the thermal expansions of the CSS during the cool down.

\section{Manufacture}

All steel parts of Cryolegs are manufactured by steel plate 1.4429 , except the tie rods. The machined parts of tie rods are made by round bar $\varnothing 90$ and $\varnothing 52$.

The ring fittings and the inner and outer rings of the Insulator bush are welded constructions. The pertinent tubes are manufactured by cold forming rolled 
plates. The foot parts of Cryolegs, bearings and base plates are manufactured by jet cut and machined steelplate.

The bellows and the GRP bush are delivered by special companies.

The supplier of the Cryoleg steel parts has to deliver the complete assembled Cryolegs.

\section{Conclusion}

The design of the Cryolegs has been developed for a variety of different functions.

The main function - statically highly loaded supporting element of the Coil System and the CSS requires a bending resistance construction of all components of the Cryolegs.

The further tasks, like balancing of bending moments, relative movements to adjacent W7-X components and the interruption of the thermal conduction of the machine base to the CSS, affected the design of the bearing components and the Insulator bush.

The material development of the Insulator bush requires extensive thermal and load tests by the supplier.

In addition a proof of the life span for at least 15 years is to be performed by the suppliers of the bearing components and the Insulator bush.

These tests are to be implemented by the suppliers according to technical specifications of the IPP.

Only after successful examination of 2 prototypes of the Cryolegs all other Cryolegs will be delivered to IPP.

\section{References}

[1] H. Jenzsch, TS Fertigung Kryoabstützungen für Stütz- und Tragstruktur, IPP document Nr. 1AAD00HD-S0009.0, 08.01.2007, Max Planck Institut für Plasmaphysik, Greifswald Germany

[2] P. Sanchez, TS GRP component of the Cryoleg, IPP document Nr. 1-AAD00HD-S0011.0, 30.03.2007, Max Planck Institut für Plasmaphysik, Greifswald Germany

[3] H. Jenzsch, TS Belastungstest Isolierbuchse für Kryoabstützungen, IPP document Nr. 1AAD00HD-S0012.1, 07.08.2007, Max Planck Institut für Plasmaphysik, Greifswald Germany

[4] J. Reich, Experimental determination of the friction factors on axial and planar bearings of the Cryolegs, IPP document Nr. 1-AAD00HDS0005.0, 31.07.2006, Max Planck Institut für Plasmaphysik, Greifswald Germany

[5] K. Egorov, Structural analysis of magnet system Cryolegs, IPP document Nr. 1-GXA-
T0042.0, 06.12.2006, Max Planck Institut für Plasmaphysik, Greifswald Germany 


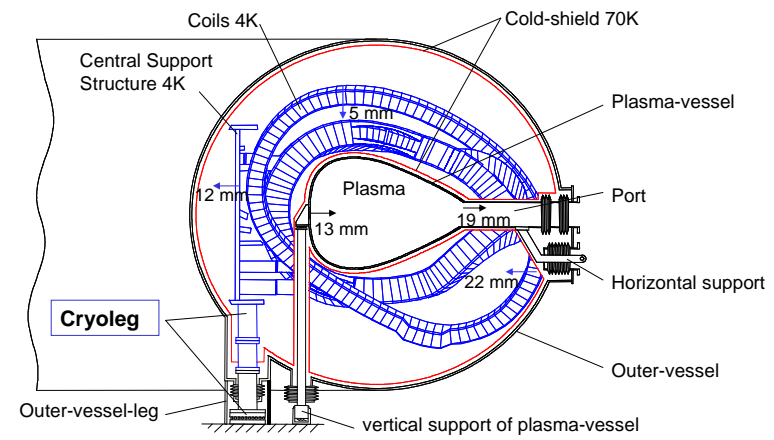

Fig. 1: Schematic view of main cryostat components of WENDELSTEIN 7-X

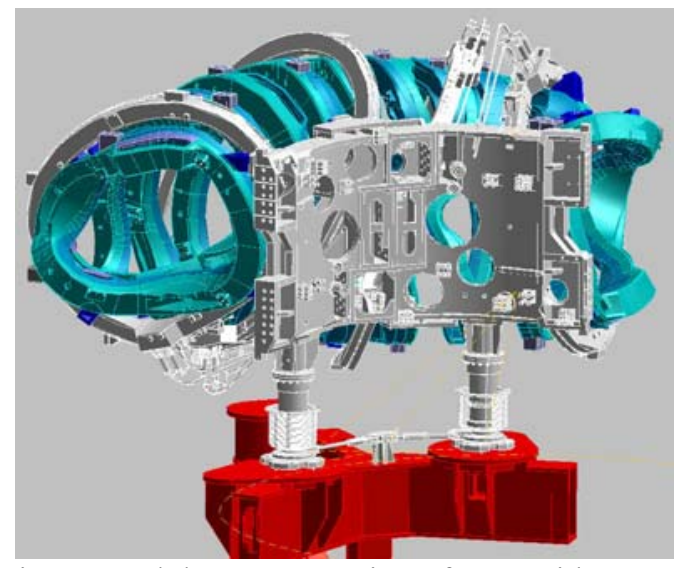

Fig. 2: Module representation of CSS with Cryoleg$\mathrm{s}$
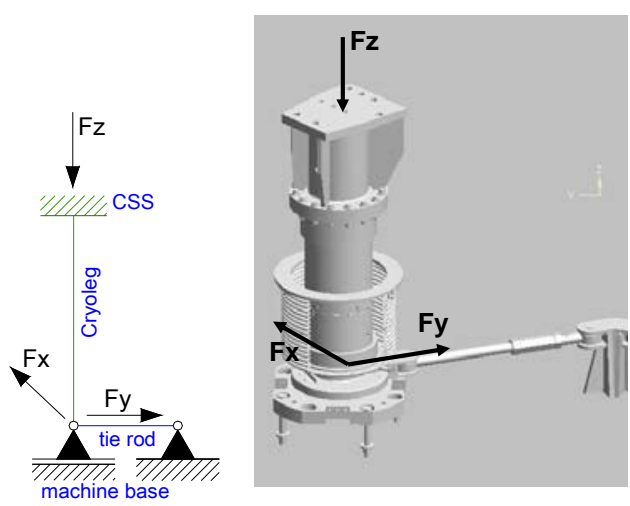

Fig. 3: Scetch of the statical system

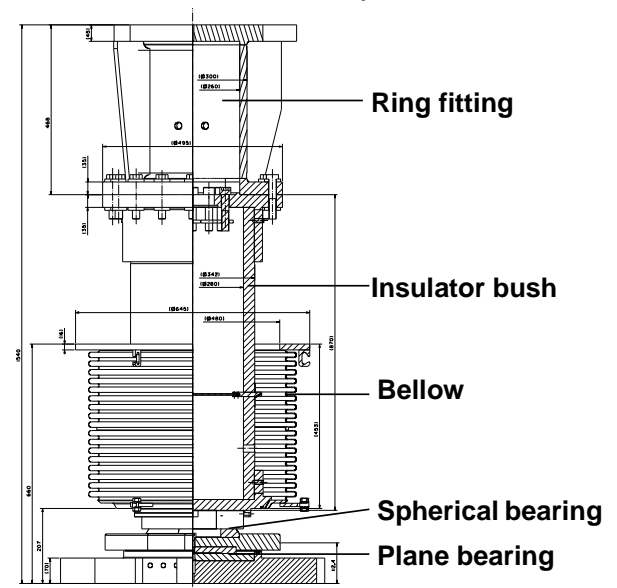

\begin{tabular}{|c|c|c|c|c|c|}
\hline + & \multicolumn{2}{|c|}{$\begin{array}{l}\text { Cryoleg upper flange } \\
\text { N1 }\end{array}$} & \multicolumn{2}{|c|}{$\begin{array}{l}\text { Cryoleg upper flange } \\
\text { N2 }\end{array}$} & $\begin{array}{l}\text { GRP tube upper } \\
\text { flange }\end{array}$ \\
\hline Flange bolt layout & \multicolumn{2}{|c|}{$\begin{array}{c}\text { 3xM33 + 3xM30 } \\
\text { Inconel } 718\end{array}$} & \multicolumn{2}{|c|}{$\begin{array}{c}\text { 3xM33 + 3xM30 } \\
\text { Inconel } 718\end{array}$} & $\begin{array}{cc}\text { Circular } & \varnothing 395 . \\
16 \times \mathrm{M} 20 & \text { A4-80 }\end{array}$ \\
\hline Bolt size & M33 & M30 & M33 & M30 & M20 \\
\hline \multirow{2}{*}{$\begin{array}{l}\text { Maximum force } \\
\text { per bolt, } \mathrm{kN} \\
\text { Maximum stress } \\
\text { in bolt, } \mathrm{MPa}\end{array}$} & 540 & 380 & 480 & 305 & 100 \\
\hline & 780 & 670 & 690 & 505 & 440 \\
\hline
\end{tabular}

Table 1: Bolt connection both Cryoleg upper flange to the CSS [5]

\begin{tabular}{|c|c|c|c|c|}
\hline & & & \begin{tabular}{|c|} 
Cryoleg \\
upper flange
\end{tabular} & $\begin{array}{c}\text { GRP tube } \\
\text { upper flange }\end{array}$ \\
\hline Axial (vertical) force & $\mathrm{Fz}$ & $\mathrm{kN}$ & 1000 & 1000 \\
\hline Radial force & $\mathrm{FX}$ & $\mathrm{kN}$ & 100 & 100 \\
\hline Toroidal force & $\mathrm{FY}$ & $\mathrm{kN}$ & 120 & 120 \\
\hline Transversal force & $\mathrm{F}$ & $\mathrm{kN}$ & 156 & 156 \\
\hline Radial Bending moment & $\mathrm{Mx}$ & $\mathrm{kNm}$ & 180 & 111 \\
\hline Toroidal Bending moment & My & $\mathrm{kNm}$ & 150 & 92 \\
\hline Bending moment & $\mathrm{M}$ & $\mathrm{kNm}$ & 234 & 144 \\
\hline
\end{tabular}

Table 2: Forces and bending moments in Cryoleg parts [5]

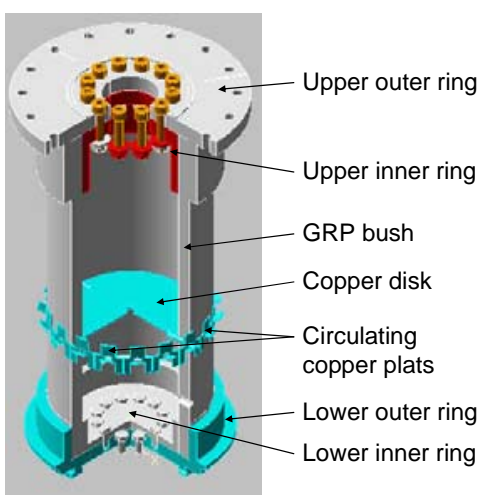

Fig. 5: Structure of insulator bush

\begin{tabular}{|l|l|}
\hline \multicolumn{2}{|c|}{ Thermal contraction from 293K to $4 \mathbf{K}(\Delta \mathrm{T}=\mathbf{2 8 9 K})$} \\
\hline vertical direction (vertical in plane) & $2,8 \cdot 10-3 \mathrm{~m} / \mathrm{m}<\alpha 1 \| * \Delta \mathrm{T}<3,2 \cdot 10-3 \mathrm{~m} / \mathrm{m}$ \\
\hline hoop direction (horizontal in plane) & $2,8 \cdot 10-3 \mathrm{~m} / \mathrm{m}<\alpha 2 \|{ }^{*} \Delta \mathrm{T}<3,2 \cdot 10-3 \mathrm{~m} / \mathrm{m}$ \\
\hline radial direction (through thickness) & $\alpha^{\perp *} \Delta \mathrm{T}<7,6 \cdot 10-3 \mathrm{~m} / \mathrm{m}$ \\
\hline
\end{tabular}

Table 3: Thermal contraction in several planes of the GRP bush [2]

\begin{tabular}{|l|l|c|c|c|}
\hline & Directions & & RT & $\mathbf{8 0 K}$ \\
\hline $\begin{array}{l}\text { Young's modulus (GPa) } \\
\text { (minimum values) }\end{array}$ & Vertical & $\mathrm{Ez}$ & 25 & 32 \\
\cline { 2 - 5 } & Hoop (toroidal) & $\mathrm{Ey}$ & 25 & 32 \\
\cline { 2 - 5 } & Radial (through thickness) & $\mathrm{Ex}$ & 11 & 20 \\
\hline
\end{tabular}

Table 4: Young's modulus several planes of the GRP bush [2] 


\begin{tabular}{|l|l|c|c|}
\hline & Directions & $\begin{array}{c}\text { Option } \\
\mathbf{A}, \mathbf{R T}\end{array}$ & $\begin{array}{c}\text { Option } \\
\mathbf{B , 8 0 K}\end{array}$ \\
\hline & Vertical tensile $\left(\sigma_{1} \| \mathrm{t}\right)$ & 300 & 400 \\
\hline \multirow{5}{*}{ Strength $(\mathbf{M P a})$} & Vertical compression $\left(\sigma_{1} \| \mathrm{c}\right)$ & 300 & 450 \\
\cline { 2 - 4 } & Hoop tensile $\left(\sigma_{2} \| \mathrm{t}\right)$ & 300 & 120 \\
\cline { 2 - 4 } & Hoop compression $\left(\sigma_{2} \| \mathrm{c}\right)$ & 300 & 100 \\
\cline { 2 - 4 } & Radial tensile $\left(\sigma_{3} \perp \mathrm{t}\right)$ & 30 & 30 \\
\cline { 2 - 4 } & Radial compression $\left(\sigma_{3} \perp \mathrm{c}\right)$ & 100 & 50 \\
\hline & Shear inter laminar $(\tau \perp)$ & 30 & 30 \\
\hline & Shear in-plane $(\tau \|)$ & 55 & 55 \\
\hline
\end{tabular}

Table 5: Strengths in several planes of the GRP bush [2]

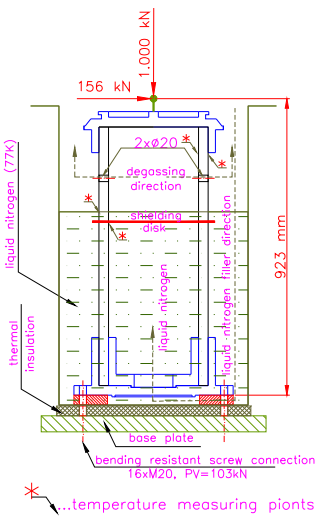

Fig. 6: Schematic experimental setup - load test [3]
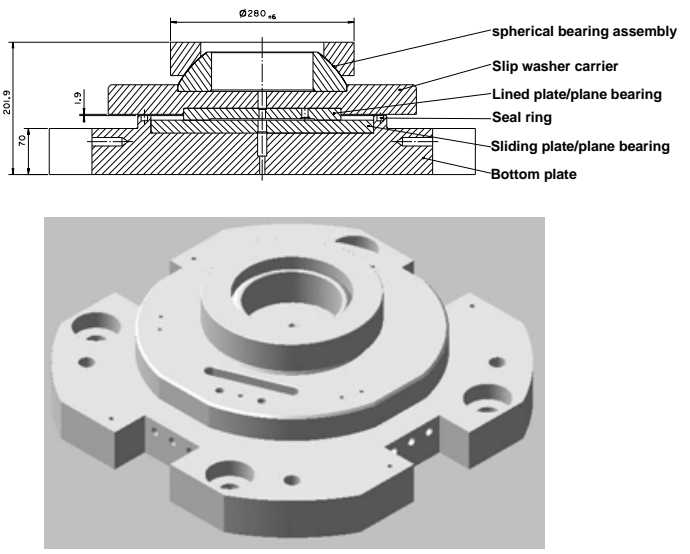

Fig. 7: Design of the bearing assembly

\begin{tabular}{|c|c|c|c|c|}
\hline $\begin{array}{c}\text { Test } \\
\text { step }\end{array}$ & $\begin{array}{c}\text { Number of } \\
\text { cycles }\end{array}$ & $\begin{array}{c}\text { Load } \\
\text { vertical } \\
(\mathrm{kN})\end{array}$ & $\begin{array}{c}\text { Motion } \\
(\mathrm{deg})\end{array}$ & $\begin{array}{c}\text { Sliding } \\
\text { velocity }\end{array}$ \\
\hline 1 & 50 & 200 & $+/-2^{\circ}$ & $1 \mathrm{~mm} / \mathrm{s}$ \\
\hline 2 & 800 & 500 & $+/-2^{\circ}$ & $1 \mathrm{~mm} / \mathrm{s}$ \\
\hline 3 & 850 & 750 & $+/-2^{\circ}$ & $1 \mathrm{~mm} / \mathrm{s}$ \\
\hline 4 & 250 & 1000 & $+/-2^{\circ}$ & $1 \mathrm{~mm} / \mathrm{s}$ \\
\hline 5 & 15 & 500 & $+/-2^{\circ}$ & $30 \mathrm{~cm} / \mathrm{h}$ \\
\hline
\end{tabular}

Table 6: Cycles to reach the maximum loads for spherical bearing [4]

\begin{tabular}{|c|c|c|c|c|}
\hline $\begin{array}{c}\text { Test } \\
\text { steps }\end{array}$ & $\begin{array}{c}\text { Number } \\
\text { of cycles }\end{array}$ & $\begin{array}{c}\text { Load } \\
\text { vertical } \\
(\mathrm{kN})\end{array}$ & $\begin{array}{c}\text { Motion } \\
(\mathrm{mm})\end{array}$ & $\begin{array}{c}\text { Sliding } \\
\text { velocity }\end{array}$ \\
\hline 1 & 50 & 200 & $+/-30$ & $1 \mathrm{~mm} / \mathrm{s}$ \\
\hline 2 & 800 & 500 & $+/-30$ & $1 \mathrm{~mm} / \mathrm{s}$ \\
\hline 3 & 850 & 750 & $+/-30$ & $1 \mathrm{~mm} / \mathrm{s}$ \\
\hline 4 & 250 & 1000 & $+/-30$ & $1 \mathrm{~mm} / \mathrm{s}$ \\
\hline 5 & 15 & 500 & $+/-30$ & $30 \mathrm{~cm} / \mathrm{h}$ \\
\hline
\end{tabular}

Table 7: Cycles to reach the maximum loads for planar bearing [4]

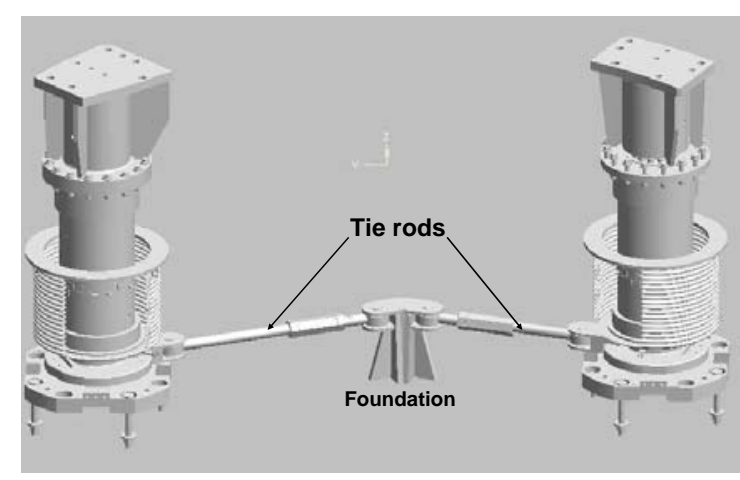

Fig. 8: Design of tie rods 